\title{
Different Coupling of Notch Loaded Rectangular Microstrip Patch Antenna for Wireless Communication System
}

\author{
Mohit Khanna $^{1}$, D.C. Dhubkarya ${ }^{2}$ \\ P.G. Student, Department of Electronics and Communication Engineering, B.I.E.T., Jhansi, U.P., India ${ }^{1}$ \\ Associate Professor, Department of Electronics and Communication Engineering, B.I.E.T., Jhansi, U.P., India ${ }^{2}$
}

\begin{abstract}
In this paper comparisonof different shapes of coupling of microstrip patch antenna is discussed.The bandwidth of proposed design antenna is $37.43 \%(2.705 \mathrm{GHz}-1.852 \mathrm{GHz})$. The antenna has been designed for $2.45 \mathrm{GHz}$ operating frequency and the result of different coupling is compared byIE3D simulationtool. The return loss is $15.698 \mathrm{~dB}$, gain of $3.7447 \mathrm{dBi}$ and Directivity of6.8002 dBi. The resonant frequency is $2.5470 \mathrm{GHz}$ which is near to our operating frequency. The antenna is fed by $50 \Omega$ Micro strip line feed.
\end{abstract}

Keywords: Microstrip patch antenna, coupling, Rectangular patch, IE3D Simulation Tool.

\section{INTRODUCTION}

Antennas are used to transmit or receive electromagnetic waves. It is a used to convert free space wave to guided wave and vice versa. During recentyears, Microstrip antenna is useful in wireless communication system [1-3].The reason for this success is its uses which are its low cost, light weight, low profile and advantage infabrication. The use of Microstrip antenna has been increased by the wireless revolution in the transfer of information.

To design the microstrip antenna we have to determine resonant frequency accurately because Microstrip antenna has narrow bandwidth and it can operate near resonant frequency.

In this paper the proposed antenna is designed using rectangular patch [5-7]and to increase the bandwidth the coupling is usedand to match the operating frequency with resonant frequency we have done different coupling [9-10] and applied microstrip line feed [11-12]. This antenna is used for resonance at $2.5470 \mathrm{GHz}$.The material used in design is Glass epoxy of dielectric constant 4.4 and loss tangent of 0.0013 . Results such as radiation pattern, gain and directivity are presented.

\section{MATHEMATICAL FORMULAS TO CALCULATE THE DESIGN DIMENSIONS OF MICROSTRIP PATCH ANTENNA}

The formula[4]which is used to calculate the dimensions of ground plane and microstrip patch in terms of length and width. The formula for calculating the width of Patch antenna is given as:

$W=\left(\frac{c}{2 f_{r}}\right)\left(\frac{\varepsilon_{r}+1}{2}\right)^{-1 / 2}$

Where: $\mathrm{c}=3 \times 10^{8} \mathrm{~ms}^{-1}, \varepsilon_{\mathrm{r}}=4.4, \mathrm{f}_{\mathrm{r}}=2.45 \mathrm{GHz}$

Formula for effective dielectric constant is given as:-

$\varepsilon_{\text {eff }}=\left(\frac{\varepsilon_{r}+1}{2}\right)+\left(\frac{\varepsilon_{r}-1}{2}\right)\left(1+\frac{12 h}{W}\right)^{-1 / 2}$

Where: $\mathrm{h}=1.6 \mathrm{~mm}$

Formula of extension in length is given as: 


$$
\Delta L=0.412 h\left(\frac{\varepsilon_{\text {eff }}+0.3}{\varepsilon_{\text {eff }}-0.258}\right)\left(\frac{\left(\frac{W}{h}\right)+0.264}{\left(\frac{W}{h}\right)+0.8}\right)
$$

Dimensional calculation of parameters such as resonant frequency $\left(f_{\mathrm{r}}\right)$, dielectric constant $\left(\varepsilon_{\mathrm{r}}\right)$, substrate thickness $(\mathrm{h})$ and loss tangent $(\tan \delta)$ and $50 \Omega$ Microstrip linefeed is used. The parameters of antenna are given in table1.

Table 1: Antenna Design Specification

\begin{tabular}{|l|l|l|}
\hline \multicolumn{1}{|c|}{ S. NO } & \multicolumn{1}{|c|}{ Antenna Parameter } & \multicolumn{1}{c|}{ Data } \\
\hline 1. & Resonant frequency $\left(\mathrm{f}_{\mathrm{r}}\right)$ & $2.45 \mathrm{GHz}$ \\
\hline 2. & Substrate thickness $(\mathrm{h})$ & $1.6 \mathrm{~mm}$ \\
\hline 3. & Dielectric constant $\left(\varepsilon_{\mathrm{r}}\right)$ & 4.4 \\
\hline 4. & Loss Tangent $(\tan \delta)$ & 0.0013 \\
\hline
\end{tabular}

\section{ANTENNA DESIGN PROCEDURE}

The parameters of ground plane are Width is $38 \mathrm{~mm}$ and Lengthis $47 \mathrm{~mm}$. The parameters of patch are Length is $28 \mathrm{~mm}$ and Widthis $37 \mathrm{~mm}$.Different couplinghaving the same structure and rectangular patch have a ring slot with inner radius $R_{1}$ of $9 \mathrm{~mm}$ and outer radius $R_{2}$ of $11 \mathrm{~mm}$. Then notching is done in patch and different couplings are used to enhance bandwidthand tomatch theresonant peak to that of design frequency.The design of calculated notch loaded coupled rectangular microstrip patch antenna with $50 \Omega$ microstrip line feed inserted at mid of length of the patch antenna is shown in Fig.1.

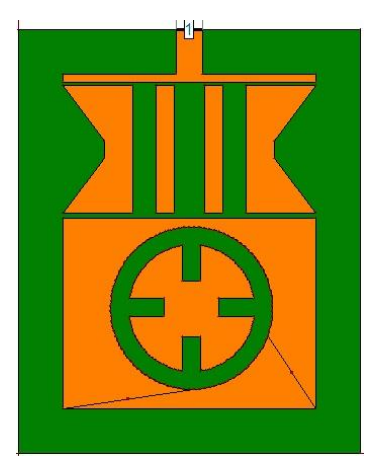

(a)

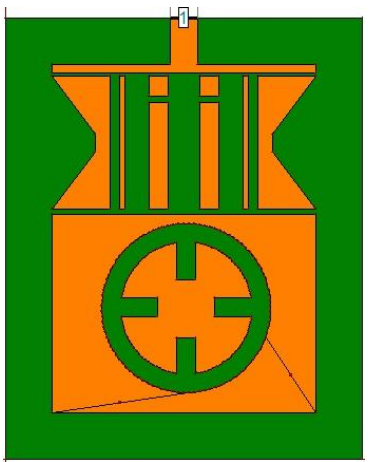

(b)

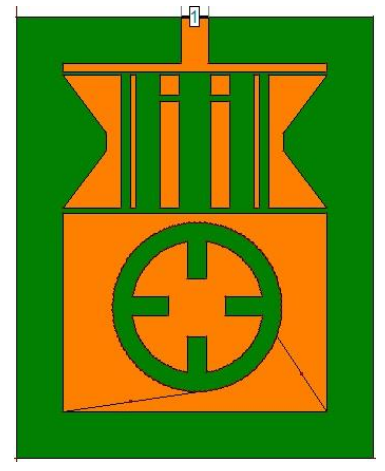

(c)

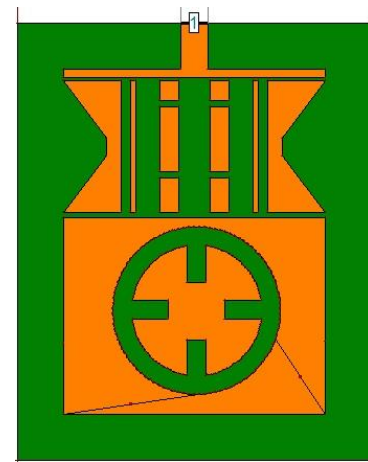

(d)

Fig.1 Design of coupling of microstrip patch antenna (a) first coupling, (b) second coupling, (c) third coupling and (d) fourth coupling.

\section{COMPARATIVE ANALYSIS}

Dimension of all couplings are different from each other so that analysis of their characteristics are comparable. Results of all the parameters such as Bandwidth, Gain and Directivity are listed in table 2. S11 of the different coupling of the microstrip patch antenna is shown in Fig.2.

From Fig.2, it is observed that the bandwidth of proposed antenna $853.7 \mathrm{MHz}$ (37.43\% fractional bandwidth) between $1.8537 \mathrm{GHz}$ to $2.7074 \mathrm{GHz}$ band and Return loss of $-15.169 \mathrm{~dB}$ at resonance frequency $2.547 \mathrm{GHz}$ has been obtained. It is also observed that operating resonance frequency $2.547 \mathrm{GHz}$ shows close value with designed resonance frequency 2.45GHz.The graph of Gain vs. Frequency of proposed antenna is shown in Fig.3. 

ISO 3297:2007 Certified

Vol. 6, Issue 5, May 2017

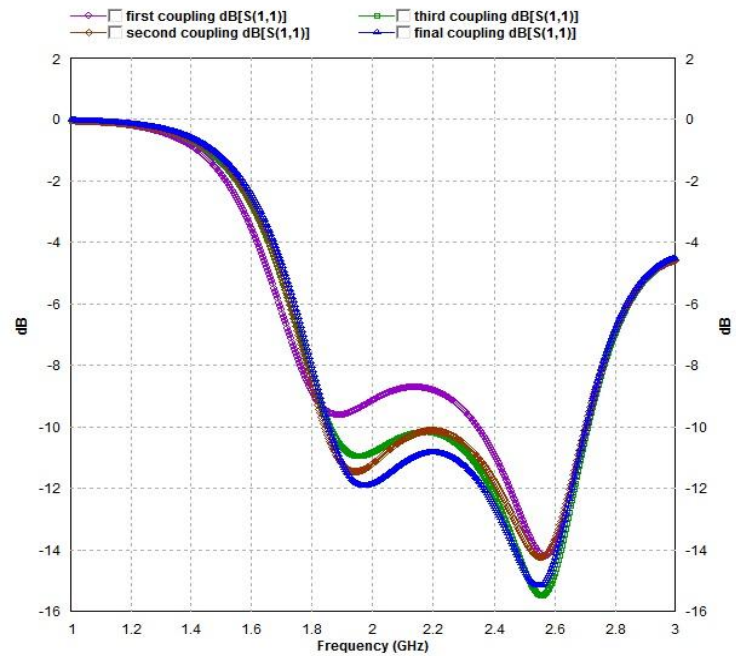

Fig.2 Comparisonof S11 of the different couplings of microstrip patch antenna

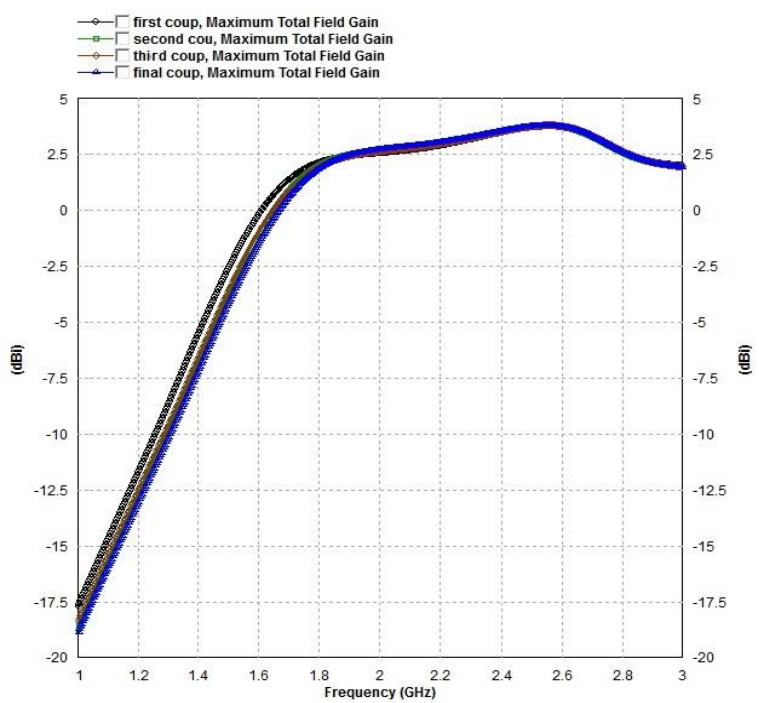

Fig.3 Comparison of Gain vs. Frequency graph of different couplings of microstrip patch antenna

The graph of Directivity vs. Frequency of proposed antenna is shown in Fig.4.

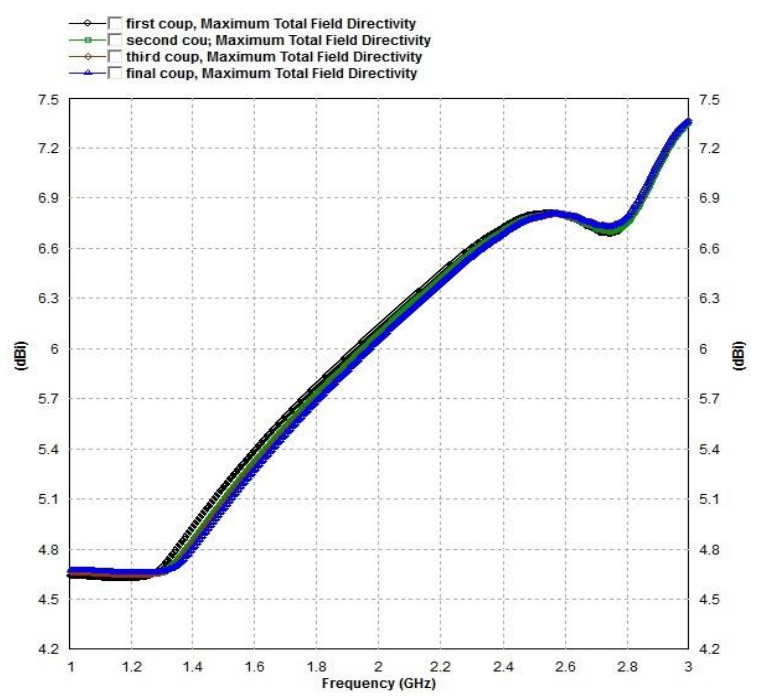

Fig.4 Comparison of Directivity vs. Frequency graph of microstrip patch antenna 
The graph of radiation pattern of optimized antenna is shown in Fig.5.

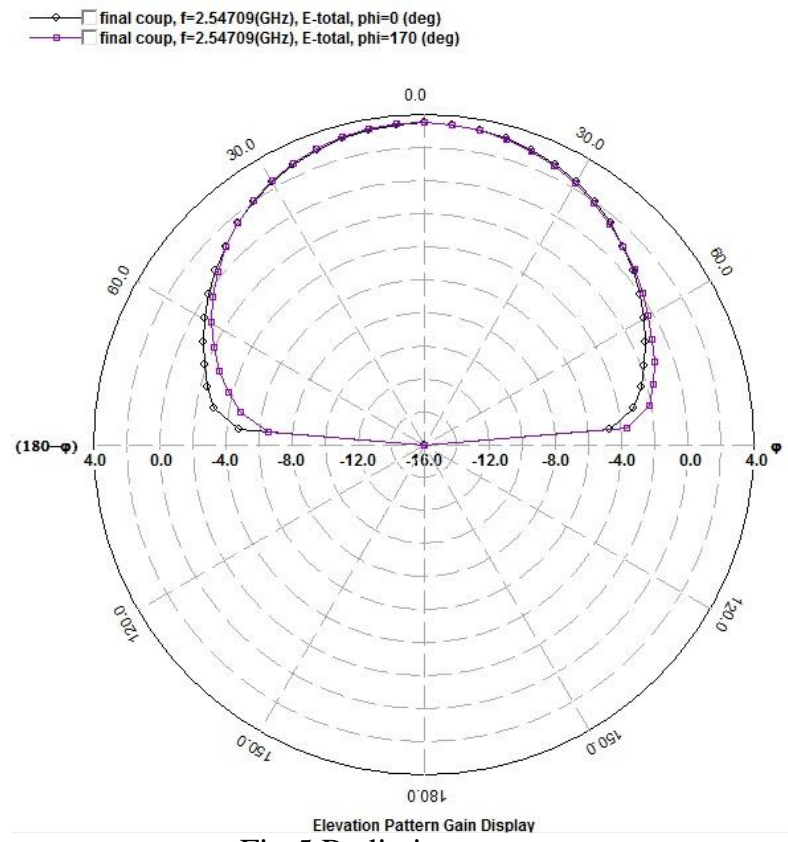

Fig.5 Radiation pattern

The radiation pattern of the proposed antenna has omnidirectional radiation pattern as shown above.

Table 2: Comparative data of different shapes of microstrip patch antenna

\begin{tabular}{|l|l|l|l|l|l|l|l|}
\hline S.No. & Patch Shape & $\begin{array}{c}\text { Lower } \\
\text { Frequency } \\
(\mathbf{G H z})\end{array}$ & $\begin{array}{c}\text { Higher } \\
\text { Frequency } \\
(\mathbf{G H z})\end{array}$ & $\begin{array}{c}\text { Resonant } \\
\text { Frequency } \\
(\mathbf{G H z})\end{array}$ & $\begin{array}{c}\text { Bandwidth } \\
(\mathbf{\%})\end{array}$ & $\begin{array}{c}\text { Gain } \\
(\mathbf{d B i})\end{array}$ & $\begin{array}{c}\text { Directivity } \\
(\mathbf{d B i})\end{array}$ \\
\hline 1 & First coupling & 2.3466 & 2.7114 & 2.5711 & 14.4246 & 3.7374 & 6.8100 \\
\hline 2 & Second coupling & 1.8376 & 2.7034 & 2.5551 & 38.1325 & 3.7301 & 6.8078 \\
\hline 3 & Third coupling & 1.8577 & 2.7154 & 2.5591 & 37.5106 & 3.7609 & 6.8068 \\
\hline 4 & Fourth coupling & 1.8537 & 2.7074 & 2.5470 & 37.4339 & 3.7447 & 6.8002 \\
\hline
\end{tabular}

We have also simulated the practical design using analyser and thus we have seen that nature of simulated graph is same as that of experimental graph. Thus we are uploading the image of hardware and comparison of simulated and experimental graph.
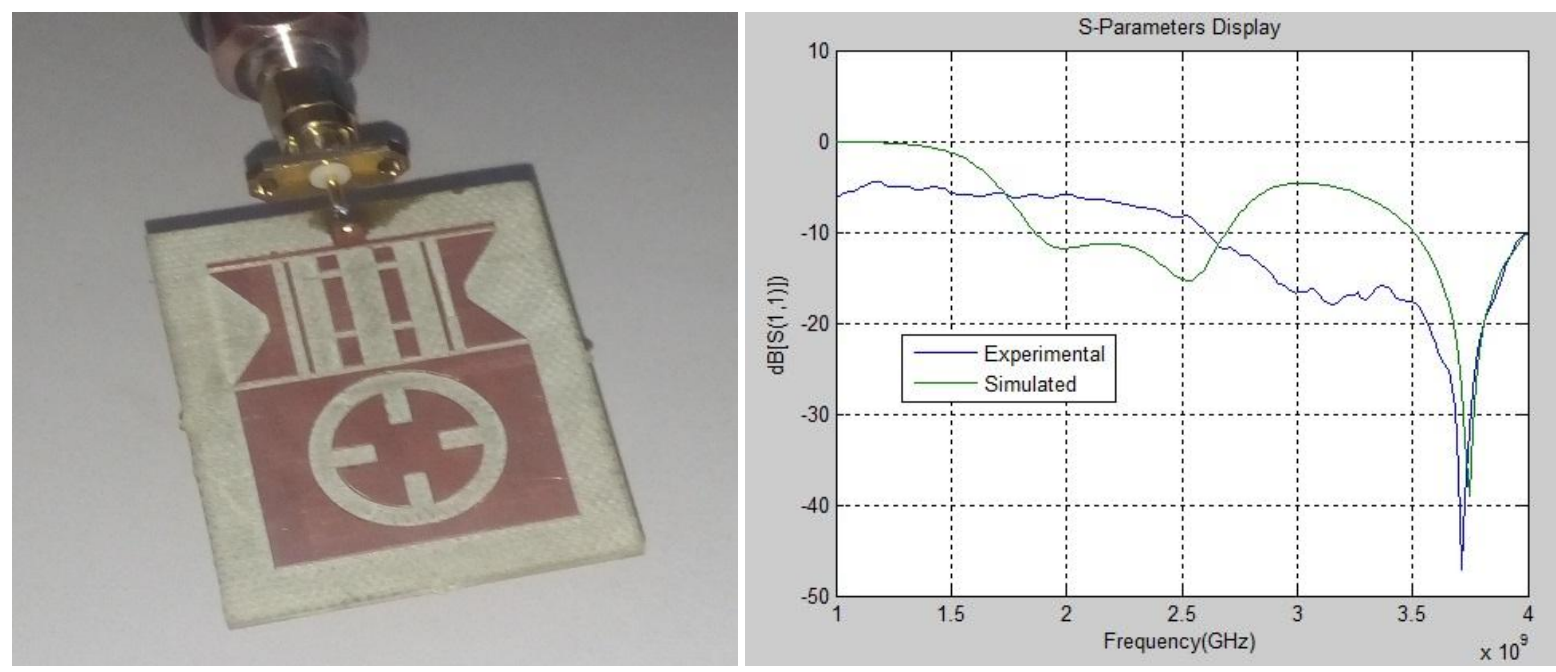


\section{IJARCCE}

\section{International Journal of Advanced Research in Computer and Communication Engineering}

ISO 3297:2007 Certified

Vol. 6, Issue 5, May 2017

\section{CONCLUSION}

From the analysis of four coupling of patch we have seen the optimized performance is obtained using fourthcoupling. Thus by varying the parameters of coupling the overall simulation results of antenna is enhanced. The resonant frequency is also matched to left side which is approximate to our operating frequency. Thus the proposed antenna design can be used in wireless communication system.

\section{REFRENCES}

[1] Marno van Rooyen, Johann W. Odendaal and Johan Joubert "High-Gain Directional Antenna for WLAN and Wi-MAX Applications" IEEE Antennas and wireless propagation letters, Vol. - 16, pp. 286-289, 2017.

[2] Yu-Jen Chou, Guo-Sheng Lin, Jun-Fu Chen, Lih-Shan Chen and Mau-PhonHoung "Design of GSM/LTE multiband application for mobile phone antennas " Electronis Letter Vol. 51 No. 17, pp. 1304-1306, 20th August 2015.

[3] N. Herscovivi, N.H. Nashua and E. Dziadek, "Omni directional antennas for wireless communication", Antennas and Propagation Society International Symposium, pp. $556-559,1999$.

[4] Constantine A. Balanis, "Antenna Theory-Analysis and Design", 3rd Edition, A John Wiley \& Sons, INC., Publication.

[5] Kai Da Xu,Yong Hong Zhang, Ronald J. Spiegel,Yong Fan, William T. Joines, Qing Huo Liu," Design of a Stub-Loaded Ring-Resonator Slot for Antenna Applications" IEEE Transactions On Antennas And Propagation, Vol. 63, No. 2,pp. 517-524, February 2015.

[6] Lixun Li, Yangbo Huang, Li Zhou, and Feixue Wang "Triple-Band Antenna With Shorted Annular Ring for High-Precision GNSS Applications" IEEE Antennas And Wireless Propagation Letters, Vol. 15, pp. 942-945, 2016.

[7] Shao-Li Zuo, Long Yang, and Zhi-Ya Zhang," Dual-Band CP Antenna With a Dual-Ring Cavity for Enhanced Beamwidth"IEEE Antennas And Wireless Propagation Letters, Vol. 14, pp. 867-870, 2015.

[8] Q. H. Abbasi, M. U. Rehman, X. D. Yang, A. Alomainy, K. Qaraqe, and E. Serpedin, "Ultra wide band band-notched flexible antenna for wearable applications," IEEE Antenna Wireless Propagation Letter, vol. 12, pp. 1606-1609, Jan. 2014.

[9] Hongye Qi,Leilei Liu,Xiaoxing Yin,Hongxin Zhao, Wlodek J. Kulesza," Mutual Coupling Suppression Between Two Closely Spaced Microstrip Antennas With an Asymmetrical Coplanar Strip Wall" IEEE Antennas And WirelessPropagation Letters, Vol. 15, pp. 191-194,2016.

[10] Xu-bao Sun and Mao Yong Cao" Low mutual coupling antenna array for WLAN application" Electronics LettersVol. 53 No. 6 pp. 368 37016th March 2017.

[11] Ashish Singh, Mohammad Aneesh, Kamakshi, Anurag Mishra and J. A. Ansari, "Analysis of F-shape micro strip line fed dual band antenna for WLAN applications," Wireless network, Vol. 20, Issue 1, pp 133-140, January 2014.

[12] Y. Sung, "A printed wide-slot antenna with a modified L-shaped micro strip line feed for wideband applications", IEEE Trans Antennas Propagation, pp.3918-3923, 2011 